\title{
Preventable clinical and psychosocial factors predicted two out of three recurrent cardiovascular events in a coronary population
}

E. Sverre ${ }^{1,2^{*}}\left(\mathbb{D}\right.$, K. Peersen ${ }^{3}$, H. Weedon-Fekjær ${ }^{4}$, J. Perk ${ }^{5}$, E. Gjertsen ${ }^{1}$, E. Husebye ${ }^{1}$, L. Gullestad ${ }^{6,7}$, T. Dammen², J. E. Otterstad ${ }^{3}$ and J. Munkhaugen ${ }^{1,2}$

\begin{abstract}
Background: The relative importance of lifestyle, medical and psychosocial factors on the risk of recurrent major cardiovascular (CV) events (MACE) in coronary patients' needs to be identified. The main objective of this study is to estimate the association between potentially preventable factors on MACE in an outpatient coronary population from routine clinical practice.

Methods: This prospective follow-up study of recurrent MACE, determine the predictive impact of risk factors and a wide range of relevant co-factors recorded at baseline. The baseline study included 1127 consecutive patients 2-36 months after myocardial infarction (MI) and/or revascularization procedure. The primary composite endpoint of recurrent MACE defined as CV death, hospitalization due to MI, revascularization, stroke/transitory ischemic attacks or heart failure was obtained from hospital records. Data were analysed using cox proportional hazard regression, stratified by prior coronary events before the index event.

Results: During a mean follow-up of 4.2 years from study inclusion (mean time from index event to end of study 5.7 years), 364 MACE occurred in 240 patients (21, 95\% confidence interval: 19 to 24\%), of which 39 were CV deaths. In multi-adjusted analyses, the strongest predictor of MACE was not taking statins (Relative risk [RR] 2.13), succeeded by physical inactivity (RR 1.73), peripheral artery disease (RR 1.73), chronic kidney failure (RR 1.52), former smoking (RR 1.46) and higher Hospital Anxiety and Depression Scale-Depression subscale score (RR 1.04 per unit increase). Preventable and potentially modifiable factors addressed accounted for 66\% (95\% confidence interval: 49 to $77 \%$ ) of the risk for recurrent events. The major contributions were smoking, low physical activity, not taking statins, not participating in cardiac rehabilitation and diabetes.
\end{abstract}

Conclusions: Coronary patients were at high risk of recurrent MACE. Potentially preventable clinical and psychosocial factors predicted two out of three MACE, which is why these factors should be targeted in coronary populations.

Trial registration: Registered at ClinicalTrials.gov: NCT02309255.

Registered at December 5th, 2014, registered retrospectively.

Keywords: Coronary heart disease, Secondary prevention, Risk factors, Psychosocial factors, Prognosis, Recurrent cardiovascular events

\footnotetext{
* Correspondence: elisbj@vestreviken.no

1 Department of Medicine, Drammen Hospital, Drammen, Norway

${ }^{2}$ Department of Behavioural Sciences in Medicine and Faculty of Medicine,

University of Oslo, Oslo, Norway

Full list of author information is available at the end of the article
}

(c) The Author(s). 2020 Open Access This article is distributed under the terms of the Creative Commons Attribution 4.0 International License (http://creativecommons.org/licenses/by/4.0/), which permits unrestricted use, distribution, and reproduction in any medium, provided you give appropriate credit to the original author(s) and the source, provide a link to the Creative Commons license, and indicate if changes were made. The Creative Commons Public Domain Dedication waiver (http://creativecommons.org/publicdomain/zero/1.0/) applies to the data made available in this article, unless otherwise stated. 


\section{Background}

Improved treatment of acute coronary syndrome with revascularization and modern medical drug therapy has reduced the short-term mortality rates and increased the number of coronary heart disease (CHD) patients in need of secondary prevention [1]. In most European countries, primary care physicians are the key actors to coordinate and provide long-term CHD management [1]. Efforts to support their clinical work is needed, as data from clinical practice in Europe have revealed poor risk factor control [2] with only few improvements over time [3]. Unhealthy lifestyle behaviour and low risk factor control is shown to contribute to the high risk of recurrent cardiovascular (CV) events observed in CHD patients [4, 5].

The relative importance of different determinants of long-term disease progression need to be studied further, since most previous studies are based on registries [4-6] with a limited number of clinical factors included. Data on lifestyle behaviour, participation in cardiac rehabilitation (CR) programs, and psychosocial factors have frequently been missing. In the recent EuroAspire IV registry study, CV comorbidities, low education and depressive symptoms were strongly and significantly associated with CV death or non-fatal myocardial infarction (MI), stroke or heart failure in an outpatient population, whereas lifestyle factors and control of lipids and blood pressure (BP) were not [7].

The current prospective study aims to estimate the relative importance of preventable and potentially modifiable clinical and psychosocial factors associated with recurrent major adverse $\mathrm{CV}$ events (MACE) in an outpatient coronary population from routine clinical practice.

\section{Methods}

\section{Design and study population}

This prospective cohort study is part of the larger NORwegian CORonary (NOR-COR) prevention project [8] (Fig. 1 - study flow chart). We identified 1789 consecutive patients aged 18-80 years with a first or recurrent coronary event in 2011-2014 from the catchment areas of the Norwegian hospitals in Drammen and Vestfold. The participation rate was $83 \%$ after excluding 423 patients with failing eligibility and omitting 239 patients who refused participation. The remaining 1127 patients were included during 2014-2015, with a median time of 16 months (range 2-36) after the coronary index event. In patients with a history of several coronary events prior to study inclusion, the last event was defined as the index event. Participants answered a comprehensive questionnaire and underwent a clinical examination with blood sample collections. Data on recurrent CV events after baseline were collected from the patients` hospital medical records in 2018, after a mean follow-up of 4.2 years. Complete follow-up data were missing in only 14 (1.2\%) patients who had moved out of the catchment area of the participating hospitals since study inclusion.

The two participating hospitals have a catchment area of 380,000 inhabitants corresponding to $7.4 \%$ of the Norwegian population. The catchment area has a representative blend of city and rural districts and is representative of Norwegian education, economy, age distribution, morbidity, and mortality $[9,10]$. The CR programs differ in content and availability between the two participating hospitals [11]. At Drammen Hospital, CR includes a multi-disciplinary 1 day "heart school", and exercise training twice per week for 6 weeks. The Hospital of Vestfold provides more comprehensive lifestyle intervention lasting for up to 6 months [11].

\section{Ethics, consent and permission}

The NOR-COR study was approved by the Regional Committee of Ethics in Medical Research (2013/1885). All patients signed a written informed consent prior to study participation.

\section{Outcome assessment}

The primary predefined [8] composite endpoint of recurrent MACE comprising CV death or readmission for myocardial infarction (MI), new revascularization procedure (PCI or CABG) due to stable/unstable angina, stroke/transitory ischemic attacks (TIA) or heart failure was obtained from the hospital records between October 10th and November 30th 2018. The registration was performed by two experienced cardiac researchers, as medical diagnoses obtained from hospital medical records are often regarded the gold standard [12].

\section{Registered study variables}

Covariates registered at baseline (2014-15, 8]:

- From hospital medical records: Age, sex, coronary history and treatment, CV comorbidity and participation in CR.

- From questionnaire: Education, smoking history including years smoked, physical activity, CV medication, self-reported family history of premature CHD ( $<55$ years male and $<65$ years females) in first degree relatives, adherence and anxiety and depression symptoms (Hospital Anxiety and Depression Scale (HADS)).

- From blood samples: Total cholesterol, low-density lipoprotein (LDL) cholesterol, high-density lipoprotein (HDL) cholesterol and C-reactive protein (CRP) (Architect ci16200, Abbott Laboratories, USA), and HbA1c (Tosoh G8, Tosoh Medics Inc., USA). All 


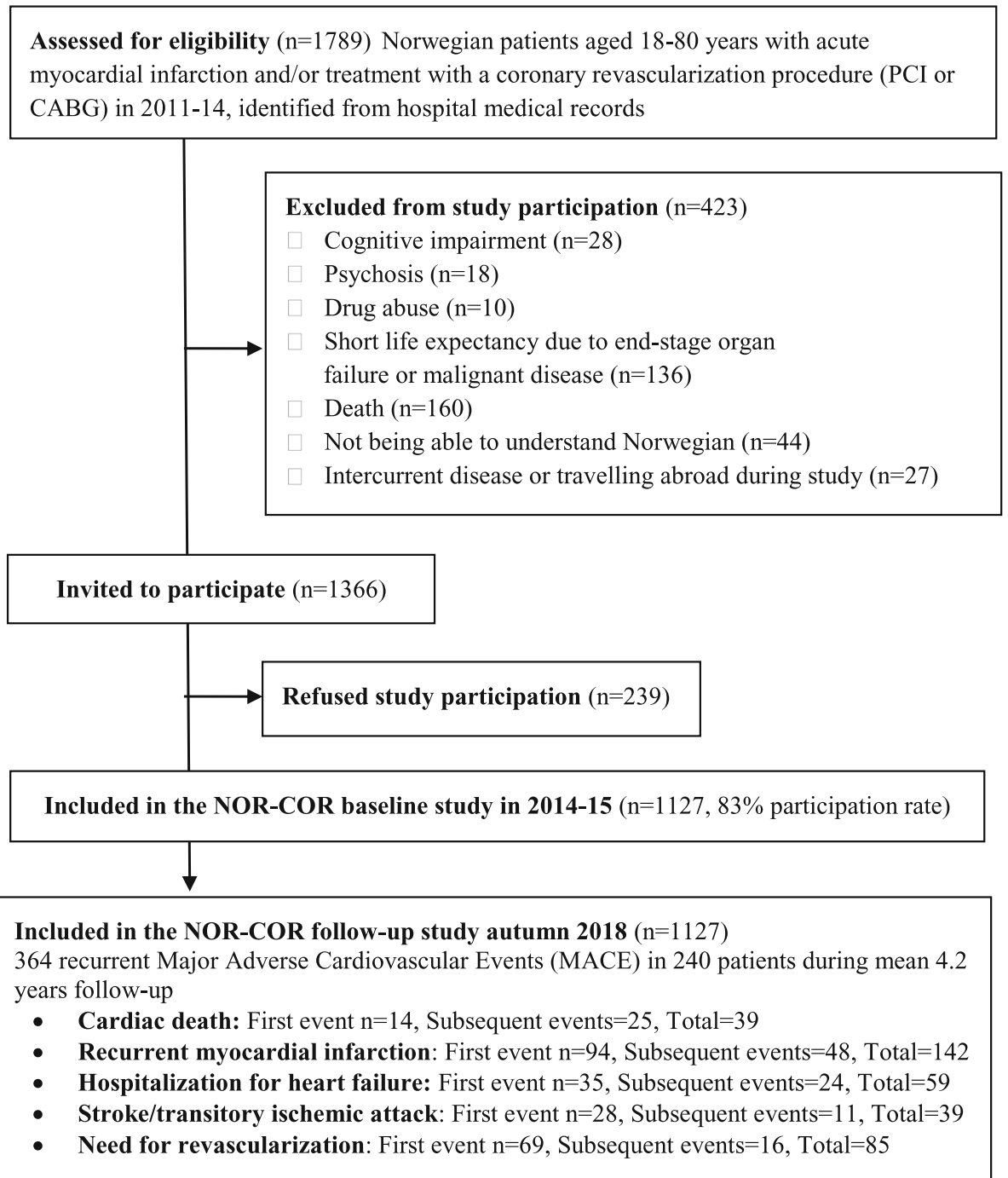

Fig. 1 Study flow chart

blood samples were analysed at Drammen hospital to avoid interlaboratory bias.

- From clinical examination: Waist circumference (nearest $0.5 \mathrm{~cm}$ ), height (nearest $0.5 \mathrm{~cm}$ ) and weight (nearest $0.5 \mathrm{~kg}$ ). Systolic and diastolic BP were measured with standardized procedure using a validated digital sphygmomanometer (Welch Allyn Connex ProBP 3400).

\section{Statistical analyses}

The descriptive baseline measurements are presented as frequencies and percentages for proportions, and as mean with standard deviation (SD) for continuous variables. Differences between groups were tested by $x^{2}$ tests and $t$-tests. Cox proportional hazard models were used to calculate relative risk (RR) and 95\% confidence interval (CI) for first and MACE event after study inclusion. Analysis time in the Cox model was defined by the time from the index event, in practice adjusting for all baseline variations in risk by time since the previous (index) coronary event (using lefttruncated data with censoring). Patients were followed until the date of a recurrent event or the end of study (1st December 2018), whichever occurred first. Data were also analysed using all MACE events, to evaluate whether results were consistent with the increased number of end-points and a more biologically mixed dataset. We first identified the relevant nonmodifiable and modifiable covariates a priori, and adjusted for these in the multivariable Cox regression analyses. Since patients with established CHD prior to inclusion were presumed to have different risk level and profile by study time, all analyses were stratified for prior CHD before the index event. 
Most applied variables had few missing values (range: 0-10\%). However, in the multivariable Cox regression analysis the combination of missing values for different variables resulted in 290 excluded patients (including 58 patients with a MACE). These missing cases lowered the statistical power of the study and could potentially have introduced a systematic bias. Hence, we also performed multivariate regression imputation under a missing at random assumption [13].

While relative risk is a good measurement of the observed risk differences across co-variables, the population impact of a given co-variable also depends on frequency of the co-variable. Hence, we also estimated the population attributable fraction (PAF) for each factor(s), measuring the factor(s) estimated contribution to the overall expected risk of MACE events [14]. For a true modifiable risk factor, this population attributable fraction equals the estimated proportion of cases that could be prevented by changing the given factor. As the effect of each co-variate in the Cox model is multiplicative, the combined PAF will be smaller than the sum of the individual PAF's, highlighting the lower potential effect of prevention when the overall risk decreases. As our PAF analyses takes the prevalence in the given population into account, it yields an estimate for the clinical significance of the given risk factor in our outpatient coronary population. Statistical analyses were performed using Stata version 15 (StataCorp LLC, College Station, USA), with the PAF calculated by the punafcc Stata add-on package [14].

\section{Results}

Mean age at study inclusion was 63.6 (SD 9.6) years and $21 \%$ were females (Table 1). The index coronary event was MI in $80 \%$ and stable or unstable CHD with angiography-verified stenosis in $20 \%$. In all, $90 \%$ had been revascularized, 97\% used at least one antiplatelet agent, $92 \%$ used a statin and $47 \%$ had participated in CR. Thirty percent $(n=336)$ had coronary event(s) prior to the index event. Thirty-four percent were obese (BMI > $\left.30 \mathrm{~kg} / \mathrm{m}^{2}\right), 21 \%$ were current smokers, and $54 \%$ were former smokers. In all, $96 \%$ of the current smokers and $75 \%$ of the former smokers had been smoking for $\geq 20$ years.

During a mean follow-up period of 4.2 (SD 0.4) years after study inclusion (mean time from index event to end of study was 5.7 (SD 0.9) years), 364 MACE events were observed in 240 (21 95\% CI, 19-24\%) patients, whereas 39 (3.4, $0.8 \%$ per year) died of CV causes. The distribution of composite endpoints is provided in Fig. 1. The risk of recurrent MACE was significantly higher in patients with CHD prior to the index event compared to those without (age adjusted $\mathrm{RR}=2.37,95 \%$ CI 1.84-3.07, $p<0.001)$.
The long-term risk of first MACE was significantly associated with increasing age, low education, former smoking, peripheral artery disease (PAD), chronic kidney failure and prior stroke, but not with gender in analyses adjusted for age and stratified by coronary events prior the index event (Table 2, model 1). Of the potentially modifiable risk factors not taking statins, low or no physical activity, diabetes, non-participation in CR, higher systolic BP and higher anxiety and depression scores (HADS) were significantly associated with MACE. Current smoking vs. never smoking (RR 1.24, 95\% CI 1.01-1.53, $p=0.048)$ was also associated with MACE (data not shown). In multi-adjusted analyses (Table 2 model 3 ), the strongest potentially modifiable predictors of MACE were not taking statins, physical inactivity and higher depression scores. Diabetes, non-participation in $\mathrm{CR}$ and higher anxiety score (HADS) were significantly associated with MACE after adjustments for coronary risk factors (Table 2, model 2), but became borderline significant after additional adjustments for CV comorbidity. In multi-adjusted sub-group analyses in patients with no CHD prior to the index event $(n=791)$, LDLcholesterol (RR 1.38 per mmol/L increase, 95\% CI 1.13$1.68, p=0.002)$ was significantly associated with MACE. As no major changes in the estimates of the potentially modifiable factors were observed, study results for all MACE are presented in Additional file 1.

The preventable and the potentially modifiable risk factors accounted for $66 \%$ (95\% CI $49-77 \%$ ) of the risk of MACE in population attributable fractions (PAF) analyses stratified for prior CHD at the index event and adjusted for age (Table 3). History of smoking (current and former) gave the highest contribution (27\%), followed by low physical activity, not participating in CR (16\%), diabetes (7\%) and not taking statins (7\%). By adding CV comorbidity, the PAF for all factors increased by only 2 to $68 \%$. The PAF for all factors did not change after excluding patients with $\mathrm{CV}$ comorbidity (data not shown).

\section{Discussion}

The risk of recurrent non-fatal CV events remained high in a chronic outpatient coronary population from routine clinical practice in Norway. Not taking statins, low or no physical activity and higher depression scores were the major potentially modifiable risk factors associated with MACE in multi-adjusted analysis. The comprehensive NOR-COR dataset, enables us to determine the relative importance of preventable and potentially modifiable factors that are regularly assessed in daily practice. Altogether, potentially preventable clinical and psychosocial factors predicted two out of three MACE in the present study. This emphasizes the great potential for reducing the patients` long-term residual $\mathrm{CV}$ mortality and morbidity risk by optimizing these factors. 
Table 1 Baseline characteristics for the study population

\begin{tabular}{|c|c|}
\hline & All patients $(n=1127)$ \\
\hline Mean age at inclusion, mean \pm SD & $63.6 \pm 9.6$ \\
\hline Females, n (\%) & $237(21.0)$ \\
\hline Low education ${ }^{\mathrm{a}}, \mathrm{n}(\%)$ & $780(70.3)$ \\
\hline Family history of coronary heart disease ${ }^{\mathrm{b}}, \mathrm{n}(\%)$ & $481(42.5)$ \\
\hline ST-elevation infarction, n (\%) & $335(29.7)$ \\
\hline Non-ST-elevation infarction, n (\%) & $561(49.8)$ \\
\hline Stable or unstable angina, $\mathrm{n}(\%)$ & $231(20.4)$ \\
\hline Percutaneous coronary intervention, n (\%) & $867(77.3)$ \\
\hline Coronary artery bypass graft operation n (\%) & $147(9.6)$ \\
\hline No revascularization, $\mathrm{n}(\%)$ & $108(9.6)$ \\
\hline$\geq 1$ coronary event prior to index event, $\mathrm{n}(\%)$ & $336(29.8)$ \\
\hline Heart failure, n (\%) & $148(13.1)$ \\
\hline Atrial fibrillation, n (\%) & $106(9.4)$ \\
\hline Peripheral artery disease, $\mathrm{n}(\%)$ & $100(8.9)$ \\
\hline Stroke or transient ischemic attack, n (\%) & $80(7.1)$ \\
\hline Chronic kidney failure (eGFR< $\left.60 \mathrm{~mL} / \mathrm{min} / 1.73 \mathrm{~m}^{2}\right), \mathrm{n}(\%)$ & 139 (13.4) \\
\hline Participation in cardiac rehabilitation, n (\%) & $526(46.7)$ \\
\hline Former smoking, n (\%) & $603(55.7)$ \\
\hline Current smoking, n (\%) & $230(21.2)$ \\
\hline Total cholesterol, mean \pm SD & $4.0 \pm 1.0$ \\
\hline Low density lipoprotein cholesterol, mean \pm SD & $2.1 \pm 0.8$ \\
\hline High density lipoprotein cholesterol, mean \pm SD & $1.1 \pm 0.3$ \\
\hline Non-high density lipoprotein cholesterol, mean \pm SD & $2.9 \pm 0.9$ \\
\hline Low physical activityc, n (\%) & $472(41.9)$ \\
\hline Physical inactivity ${ }^{c}$ n (\%) & $197(18.0)$ \\
\hline Diabetes mellitus, n (\%) & $189(16.9)$ \\
\hline $\mathrm{HbA} 1 \mathrm{c}$ in non-diabetic patients, mean $\pm \mathrm{SD}$ & $5.8 \pm 0.5$ \\
\hline $\mathrm{HbA} 1 \mathrm{c}$ in diabetic patients, mean $\pm \mathrm{SD}$ & $7.6 \pm 1.4$ \\
\hline Systolic blood pressure $\mathrm{mmHg}$, mean $\pm \mathrm{SD}$ & $138 \pm 19.0$ \\
\hline Diastolic blood pressure $\mathrm{mmHg}$, mean $\pm \mathrm{SD}$ & $82 \pm 8.8$ \\
\hline Waist circumference $\mathrm{cm}$, mean $\pm \mathrm{SD}$ & $102.5 \pm 12.3$ \\
\hline Body Mass index in $\mathrm{kg} / \mathrm{m}^{2}$, mean $\pm \mathrm{SD}$ & $28.6 \pm 4.5$ \\
\hline C-reactive protein $\mathrm{mg} / \mathrm{l}$, mean $\pm \mathrm{SD}$ & $2.5 \pm 2.7$ \\
\hline At least 1 antiplatelet agent, $n(\%)$ & $1096(97.2)$ \\
\hline Statin treatment, $\mathrm{n}(\%)$ & $1036(91.9)$ \\
\hline Beta-blocker treatment, n (\%) & $815(72.3)$ \\
\hline ACE inhibitor or ARB treatment, $n(\%)$ & $561(49.8)$ \\
\hline HADS Anxiety sum score, mean \pm SD & $4.8 \pm 3.2$ \\
\hline HADS Depression sum score, mean \pm SD & $3.9 \pm 3.2$ \\
\hline
\end{tabular}

SD Standard deviation, HADS Hospital Anxiety and Depression score, eGFR estimated glomerular filtration rate, $A C E$ Angiotensin converting enzyme, $A R B$ Angiotensin receptor blocker

${ }^{\mathrm{a} C o m p l e t i o n}$ of primary or secondary school only

${ }^{b}$ Family history of coronary heart disease was defined as first degree relatives with coronary heart disease before the age of 55 years for men and 65 years for women

${ }^{\mathrm{c}}$ Adequate physical activity is defined as $\geq$ moderate physical activity for $30 \mathrm{~min} 2-3$ times a week, low physical activity is defined as $<$ moderate physical activity for 30 min 2-3 times a week, and physical inactivity as physical activity $<1$ time a week 
Table 2 Risk of first recurrent cardiovascular event in coronary patients, estimated by Cox proportional hazard regression

\begin{tabular}{|c|c|c|c|c|c|c|}
\hline & \multicolumn{2}{|l|}{ Model $1^{\mathrm{a}}$} & \multicolumn{2}{|l|}{ Model $2^{b}$} & \multicolumn{2}{|l|}{ Modell $3^{c}$} \\
\hline & $\overline{\mathrm{RR}}$ & $\overline{p \text {-value }}$ & $\overline{\mathrm{RR}}$ & $\overline{p \text {-value }}$ & $\overline{\mathrm{RR}}$ & $p$-value \\
\hline Age per 10 years & $1.15(1.00,1.32)$ & 0.050 & $1.12(0.96,1.30)$ & 0.146 & $1.02(0.87,1.20)$ & 0.792 \\
\hline Male sex & $0.85(0.63,1.15)$ & 0.299 & $0.93(0.67,1.27)$ & 0.638 & $0.89(0.64,1.23)$ & 0.472 \\
\hline Low education ${ }^{d}$ & $1.68(1.23,2.31)$ & 0.001 & $1.58(1.15,2.11)$ & 0.005 & $1.51(1.09,2.09)$ & 0.014 \\
\hline Never smoking & 1 (reference) & & 1 (reference) & & 1 (reference) & \\
\hline Former smoking & $1.54(1.09,2.19)$ & 0.017 & $1.51(1.06,2.16)$ & 0.024 & $1.46(1.01,2.10)$ & 0.043 \\
\hline Current smoking & $1.48(0.97,2.24)$ & 0.067 & $1.32(0.86,2.02)$ & 0.205 & $1.13(0.73,1.76)$ & 0.587 \\
\hline Adequate physical activity ${ }^{\mathrm{e}}$ & 1 (reference) & & 1 (reference) & & 1 (reference) & \\
\hline Low physical activity & $1.36(1.00,1.85)$ & 0.051 & $1.37(1.00,1.87)$ & 0.049 & $1.35(0.97,1.87)$ & 0.071 \\
\hline Physical inactivity & $1.84(1.29,2.61)$ & 0.001 & $1.78(1.23,2.58)$ & 0.002 & $1.73(1.18,2.55)$ & 0.005 \\
\hline LDL cholesterol per mmol/L increase & $1.17(1.00,1.38)$ & 0.057 & $1.17(0.99,1.37)$ & 0.063 & $1.14(0.97,1.35)$ & 0.119 \\
\hline Diabetes mellitus & $1.64(1.22,2.19)$ & 0.001 & $1.47(1.09,2.00)$ & 0.013 & $1.35(0.99,1.84)$ & 0.061 \\
\hline Systolic blood pressure per $10 \mathrm{mmHg}$ increase & $1.06(0.99,1.13)$ & 0.111 & $1.06(0.99,1.13)$ & 0.088 & $1.06(0.99,1.13)$ & 0.114 \\
\hline Waist circumference per $10 \mathrm{~cm}$ increase & $1.24(1.00,1.54)$ & 0.048 & $1.06(0.84,1.33)$ & 0.639 & $1.05(0.83,1.33)$ & 0.687 \\
\hline C-reactive protein per $\mathrm{mg} / \mathrm{L}$ increase & $1.02(0.98,1.06)$ & 0.346 & & & & \\
\hline Not participating in cardiac rehabilitation & $1.42(1.09,1.86)$ & 0.010 & $1.32(1.01,1.74)$ & 0.045 & $1.29(0.97,1.70)$ & 0.077 \\
\hline Not taking statin & $2.08(1.43,3.03)$ & $<0.001$ & $2.06(1.33,3.20)$ & 0.001 & $2.13(1.36,3.36)$ & 0.001 \\
\hline Heart failure & $1.21(0.86,1.69)$ & 0.281 & & & & \\
\hline Peripheral artery disease & $1.96(1.39,2.75)$ & $<0.001$ & $1.78(1.26,2.52)$ & 0.001 & $1.73(1.21,2.49)$ & 0.003 \\
\hline Stroke or transient ischemic attack & $1.43(0.94,2.16)$ & 0.091 & $1.28(0.84,1.95)$ & 0.248 & $1.12(0.72,1.74)$ & 0.617 \\
\hline Chronic kidney failure (eGFR<60 mL/min/1.73m²) & $1.84(1.32,2.35)$ & $<0.001$ & $1.62(1.16,2.27)$ & 0.005 & $1.52(1.08,2.14)$ & 0.016 \\
\hline HADS Anxiety sum per unit increase & $1.04(1.01,1.08)$ & 0.017 & $1.03(1.00,1.07)$ & 0.031 & $1.03(1.00,1.07)$ & 0.058 \\
\hline HADS Depression sum per unit increase & $1.06(1.02,1.10)$ & 0.002 & $1.05(1.01,1.09)$ & 0.045 & $1.04(1.00,1.09)$ & 0.028 \\
\hline
\end{tabular}

RR Relative risk, LDL Low density lipoprotein cholesterol, eGFR estimated glomerular filtration rate, HADS Hospital anxiety and depression score

All analyses based on imputed dataset

${ }^{a}$ Adjusted for age. Analysis is stratified by prior coronary events before the index event or not

${ }^{b}$ Adjusted for coronary risk factors with $\mathrm{p}$-value $<0.1$ in crude or age adjusted analyses (smoking, LDL cholesterol, physical activity and systolic blood pressure) in addition to adjustments in Model 1

cAdjusted for cardiovascular comorbidity with $p$-value $<0.1$ in crude analyses (stroke, peripheral artery disease and kidney failure) in addition to adjustments in Model 2

${ }^{\mathrm{d} C}$ Completion of primary or secondary school only

${ }^{\mathrm{e}}$ Adequate physical activity is defined as $\geq$ moderate physical activity for $30 \mathrm{~min} 2-3$ times a week, low physical activity is defined as $<$ moderate physical activity for 30 min 2-3 times a week, and physical inactivity as physical activity $<1$ time a week

The study population was $<80$ years and most patients were revascularized and received the recommended drug treatment which is subsidized in Norway. Despite this, more than 2 out of 10 patients suffered a MACE during a 4 years follow-up period, and $16 \%$ had a non-fatal MI, stroke or $\mathrm{CV}$ death giving a yearly rate of $3.8 \%$. Our results are in line with older data from the REACH registry reporting a prevalence of recurrent first CV death, $\mathrm{MI}$ and stroke of $4.5 \%$ per year (18\% over 4 years) in patients with established CVD. In contrast, the EuroAspire IV register, with similar inclusion criteria, found a yearly rate of first CV death, MI and stroke of only 2.6\% (5.1\% over 2 years). However, EuroAspire IV had an inclusion rate of only $49 \%$ [7] whereas $60 \%$ of the MACE were obtained by self-rapport questionnaires which may have underestimated the true prevalence. In line with our results, there was a yearly incidence of $1.1 \% \mathrm{CV}$ deaths in
EuroAspire IV. The high levels of MACE along with a low incidence of $\mathrm{CV}$ deaths found in both studies, most probably reflect effective management of recurrent nonfatal MACE.

Current smoking was not significantly associated with MACE compared to former and never smoking although a trend towards increased risk was observed. Former smoking, however, was prevalent and significantly associated with MACE. Even though former smoking may be regarded as a non-modifiable factor, it is a preventable risk factor in the CHD population. Smoking history combining former and current smoking, accounted for the highest attributable risk fraction (27\%) for recurrent MACE. In line with our results, EuroAspire IV [7], did not find a significant association between current smoking and MACE. Possible explanations might be a long history of smoking in those quitting prior to study 
Table 3 Attributable risk fraction associated with preventable and potentially modifiable risk factors

\begin{tabular}{|c|c|c|}
\hline \multicolumn{3}{|c|}{ Attributable risk fraction (95\% confidence interval) } \\
\hline History of smoking & $27 \%$ & $(5,44)$ \\
\hline $\mathrm{LDL}$ cholesterol $\geq 1.8 \mathrm{mmol} / \mathrm{L}$ & $-4 \%$ & $(-23,12)$ \\
\hline Low physical activity ${ }^{a}$ & $21 \%$ & $(5,34)$ \\
\hline Diabetes mellitus & $7 \%$ & $(1,13)$ \\
\hline Blood pressure $\geq 140 / 90(80) \mathrm{mmHg}$ & $7 \%$ & $(-6,19)$ \\
\hline Central obesity ${ }^{\mathrm{b}}$ & $11 \%$ & $(-8,28)$ \\
\hline Not participating in cardiac rehabilitation & $16 \%$ & $(1,28)$ \\
\hline Not taking statin & $7 \%$ & $(4,9)$ \\
\hline HADS Anxiety or Depression score $\geq 8$ & $7 \%$ & $(0,15)$ \\
\hline All risk factors combined & $66 \%$ & $(49,77)$ \\
\hline
\end{tabular}

LDL Low density lipoprotein, HADS Hospital anxiety and depression scale Analyses based on imputed dataset

aLess than $30 \mathrm{~min}$ of moderate activity 2-3 times a week

${ }^{b}$ Waist circumference $\geq 102 \mathrm{~cm}$ in males and $\geq 88 \mathrm{~cm}$ in females

inclusion and too short follow-up to see the effect of smoking cessation. The susceptibility of smoking also differs individually [14], and those patients most susceptible to the negative effects of smoking, might to a larger extent have died prior to study inclusion. Smoking was significantly associated with increased risk of death, but not readmissions in a large Swedish registry study [4]. Nevertheless, the benefit of smoking cessation in CHD prevention is strongly documented [15].

Physical inactivity $(<1$ time/week) was a strong predictor of MACE. Low physical activity $(<30 \mathrm{~min} 2-3$ times/week) was also associated with MACE after adjusting for other $\mathrm{CV}$ risk factors, but the association became borderline significant ( $p=0.071)$ after adjusting for CV comorbidity. The EuroAspire IV study did not find low physical activity to be significantly associated with MACE, but low physical activity was defined differently [7]. However, several observational studies have identified physical inactivity as an important prognostic factor in CHD patients $[4,16]$. Other studies have found that the greatest effect on CHD prognosis was achieved by increasing the activity level from inactivity to low activity $[17,18]$. Therefore a larger effort should be made to help inactive patients become somewhat active, even though they may not reach guideline recommendations [1].

A recent review found an effect of $\mathrm{CR}$ on the risk of new $\mathrm{CV}$ events even in the modern era of MI treatment [19]. However, the population in RCT studies might differ from the general population with chronic CHD. We had a participation rate of $47 \%$ in $C R$, which is higher than the national average of $28 \%$ [20]. Non-participation in CR was associated with MACE in analyses adjusted for age and $\mathrm{CV}$ risk factors. The effect of CR is thereby likely not only limited to the effect on risk factor control. Factors such as better medical adherence [11] and effect on depressive symptoms [21] might explain some of the additional effect. When adjusting for CV comorbidities, CR nonparticipation becomes borderline significant $(p=0.077$ ).

We found no significant association between higher LDL-cholesterol levels and MACE. This can be explained by the high prescription rate of statins and an average LDL-cholesterol level of $2.1 \mathrm{mmol} / \mathrm{L}$ at baseline. It is previously shown that the effect of LDL-cholesterol on cardiac prognosis in chronic CHD is most pronounced in those with levels above $2.6 \mathrm{mmol} / \mathrm{L}$ [22] However, increasing LDL-cholesterol level was significantly associated with recurrent MACE in the subgroup with one coronary event only. These patients are younger and have less comorbidity which may explain the relatively stronger effect on $\mathrm{CV}$ prognosis. Not taking a statin was the strongest determinant of recurrent MACE, and remained significant after adjusting for other risk factors and CV comorbidities. Taking statin treatment was also protective of recurrent $\mathrm{CV}$ events in EuroAspire IV [7] and REACH [5] registries. Thus, novel strategies to ensure prescription of and long-term adherence to statin therapy seems to be even more important than further LDL-cholesterol reduction in an outpatient CHD population. Muscular side-effects are the major cause of non-adherence/discontinuation of statins [23]. Thus, further research into statin associated muscle symptoms and the identification of a biomarker is of vital importance [23].

Several studies have found an "obesity paradox", where overweight and moderately obese patients have better prognosis than those with normal weight [24]. Increasing waist circumference was significantly associated with MACE, but not when adjusted for other CV risk factors. In line with our results, EuroAspire IV [2] found a trend towards higher risk of MACE with increasing waist circumference. Diabetes, mainly type 2 (93\%) was, associated with MACE in all adjusted analyses except from borderline significance $(p=0.061)$ after adjusting for $\mathrm{CV}$ comorbidity. Systolic BP levels were significantly associated with MACE only in crude (1.07, 95\% CI 1.00-1.15 per $10 \mathrm{mmHg}, p=0.045$ ), but not adjusted analyses, as observed in EuroAspire IV [7]. In line with obesity, the effect of BP on MACE might have been partly modified through other risk factors like diabetes, $\mathrm{CV}$ comorbidity and increasing age.

Higher HADS sub-scores of both depression and anxiety were associated with increased risk of MACE in analyses adjusted for coronary risk factors, suggesting that the effect of these factors on MACE risk are not mediated through poor risk factor control alone. A wide range of mechanisms linking psychosocial factors to CHD have been identified, such as proinflammation, endothelial dysfunction and changes in the hypothalamic-pituitary-adrenal and autonomic nervous system 
[25]. Even though treatment of depression so far has yielded limited and uncertain effect on prognosis [26], depression and other psychosocial factors are important to address as they may act as barriers to both lifestyle changes and treatment adherence [25, 27].

The NOR-COR population was consecutively recruited and the participation rate was high (83\%). Socioeconomic status and mortality rate were in line with national data [9]. Another strength of the study is that all MACE have been extracted from the hospital records by experienced cardiologists with only 14 out of 1127 patients being lost to follow-up. Since the hospital records are automatically linked to the Population Registry in Norway, no fatal cases are likely to have been overlooked. The present study has limitations. We may have missed some MACE occurring outside the catchment area of the participating hospitals. However, as hospital discharge reports are normally sent to the local hospital in Norway, the risk is low. By design, patients were included in NOR-COR 2-36 months after the index event, which may introduce a survival bias, as 160 patients had died between time of event and inclusion. These patients may have had even poorer risk factor control or more comorbidity than those included.

Although we have performed a comprehensive evaluation of determinants associated with recurrent MACE, data on additional potentially modifiable factors like fasting blood glucose, the use of metformin and pack years smoked are not available.

\section{Conclusions}

The risk of recurrent $\mathrm{CV}$ events remained high in an outpatient coronary population, particularly in the presence of CV comorbidity. Not taking statin therapy, insufficient physical activity, smoking, diabetes, higher depression scores and non-participation in CR were the major preventable and potentially modifiable factors associated with MACE. Potentially preventable clinical and psychosocial factors predicted two out of three MACE, and efforts that target the factors identified may reduce the incidence of recurrent $\mathrm{CV}$ events in outpatient coronary populations.

\section{Supplementary information}

Supplementary information accompanies this paper at https://doi.org/10 1186/s12872-020-01368-6.

Additional file 1: Long-term risk of all recurrent cardiovascular events in an outpatient coronary population, estimated by Cox proportional hazard models.

\section{Abbreviations}

ACEl: Angiotensin converting enzyme inhibitor; ARB: Angiotensin receptor blocker; BP: Blood pressure; CABG: Coronary artery bypass graft operation; CHD: Coronary heart disease; $\mathrm{Cl}$ : Confidence interval; CR: Cardiac rehabilitation; CRP: C-reactive protein; CV: Cardiovascular; CVD: Cardiovascular disease; eGFR: Estimated glomerular filtration rate; HADS: Hospital anxiety and depression score; LDL: Low density lipoprotein cholesterol; MACE: Major adverse cardiovascular events; MI: Myocardial infarction; PAD: Peripheral artery disease; PAF: Population attributable fraction; PCI: Percutaneous coronary intervention; RCT: Randomized clinical trial; RR: Relative risk; SD: Standard deviation; TIA: Transitory ischemic attacks

\section{Acknowledgments}

The NOR-COR project originates from the Department of Medicine, Drammen Hospital Trust and the study is carried out at Drammen and Vestfold Hospitals. The study concept is developed in collaboration with communities at the University of Oslo. The authors thank the study patients for participating and the study personnel for their invaluable contribution.

\section{Authors' Contributions}

$J P, T D, L G, E G, E H, J E O$ and JM contributed to the design of the work. ES, $H W F, K P$ and JM conducted the analyses and all authors contributed to the interpretation of the data. ES drafted the manuscript. All authors critically revised the manuscript, gave final approval and agree to be accountable for all aspects of the work ensuring integrity and accuracy.

\section{Funding}

The author(s) disclosed receipt of the following financial support for the research, authorship, and/or publication of this article: The study was funded by grants from Drammen Hospital (grant 1703001 project 9603003) and the hospital of Vestfold (grant 703110 project 19440). Elise Sverre receives funding from the Norwegian ExtraFoundation. The funding bodies have no role in the design of the study, data collection, analysis, or interpretation of data or in writing the manuscript.

\section{Availability of data and materials}

According to Norwegian legislation, the Norwegian Data Protection Authority and the Committee of Ethics, we are not allowed to share original study data publicly. However, except for anthropometric data, the other essential data by which the conclusions in the article are based will be provided upon reasonable request to the corresponding author.

\section{Ethics approval and consent to participate}

All participants gave a written informed consent before study participation. The NOR-COR study was approved by the Regional Committee for Medical and Health Research Ethics in the South East Region of Norway (REK Sør-Øst) 12. February 2014 (2013/1885). The authority of Regional Committee for Medical and Health Research Ethics is delegated from the Ministry of Health and Care Services.

\section{Consent for publication}

Not applicable.

\section{Competing interests}

The authors declared no potential conflicts of interest with respect to the research, authorship, and/or publication of this article.

\section{Author details}

${ }^{1}$ Department of Medicine, Drammen Hospital, Drammen, Norway. ${ }^{2}$ Department of Behavioural Sciences in Medicine and Faculty of Medicine, University of Oslo, Oslo, Norway. ${ }^{3}$ Department of Medicine, Vestfold Hospital, Oslo, Norway. ${ }^{4}$ Oslo Centre for Biostatistics and Epidemiology, Research Support Services, Oslo University Hospital, Oslo, Norway. ${ }^{5}$ Department of Cardiology, Public Health Department Linnaeus University, Kalmar, Sweden. ${ }^{6}$ Department of Cardiology, Oslo University Hospital Rikshospitalet, Faculty of Medicine, University of Oslo, Oslo, Norway. ${ }^{7}$ KG Jebsen Cardiac Research Center, Oslo University Hospital Ullevål, Oslo, Norway.

Received: 6 August 2019 Accepted: 30 January 2020

Published online: 05 February 2020

\section{References}

1. Piepoli MF, Hoes AW, Agewall S, Albus C, Brotons C, Catapano AL, Cooney MT, Corra U, Cosyns B, Deaton C, et al. 2016 European Guidelines on cardiovascular disease prevention in clinical practice: The Sixth Joint Task Force of the European Society of Cardiology and Other Societies on 
Cardiovascular Disease Prevention in Clinical Practice (constituted by representatives of 10 societies and by invited experts): Developed with the special contribution of the European Association for Cardiovascular Prevention \& Rehabilitation (EACPR). Eur J Prev Cardiol. 2016;23(11):Np1np96.

2. Kotseva K, De Backer G, De Bacquer D, Ryden L, Hoes A, Grobbee D, Maggioni A, Marques-Vidal P, Jennings C, Abreu A, et al. Lifestyle and impact on cardiovascular risk factor control in coronary patients across 27 countries: results from the European Society of Cardiology ESC-EORP EUROASPIRE V registry. Eur J Prev Cardiol. 2019. https://doi.org/10.1177/ 2047487318825350.

3. Santos RD. Inadequate control of atherosclerotic cardiovascular disease risk factors in Europe: EUROASPIRE repeats itself. Eur J Prev Cardiol. 2019. https://doi.org/10.1177/2047487319831476.

4. Ek A, Ekblom O, Hambraeus K, Cider A, Kallings LV, Borjesson M. Physical inactivity and smoking after myocardial infarction as predictors for readmission and survival: results from the SWEDEHEART-registry. Clin Res Cardiol. 2019;108(3):324-32.

5. Bhatt DL, Eagle KA, Ohman EM, Hirsch AT, Goto S, Mahoney EM, Wilson PW Alberts MJ, D'Agostino R, Liau CS, et al. Comparative determinants of 4-year cardiovascular event rates in stable outpatients at risk of or with atherothrombosis. JAMA. 2010;304(12):1350-7

6. Jernberg T, Hasvold P, Henriksson M, Hjelm H, Thuresson M, Janzon M. Cardiovascular risk in post-myocardial infarction patients: nationwide real world data demonstrate the importance of a long-term perspective. Eur Heart J. 2015;36(19):1163-70.

7. De Bacquer D, De Smedt D, Kotseva K, Jennings C, Wood D, Ryden L, Gyberg V, Shahim B, Amouyel P, Bruthans J, et al. Incidence of cardiovascular events in patients with stabilized coronary heart disease: the EUROASPIRE IV follow-up study. Eur J Epidemiol. 2019;34(3):247-58.

8. Munkhaugen J, Sverre E, Peersen K, Gjertsen E, Gullestad L, Moum T, Otterstad JE, Perk J, Husebye E, Dammen T. The role of medical and psychosocial factors for unfavourable coronary risk factor control. Scand Cardiovasc J. 2016:50(1):1-8. https://doi.org/10.3109/14017431.2015.1111408.

9. Accessed 25 Nov 2015 at https://www.ssb.no/statistikkbanken and https:// www.nav.no/no/NAV+og+samfunn/Statistikk/AAP+nedsatt+arbeidsevne+ og+uforetrygd+-+statistikk/Uforetrygd.

10. Accessed 1 Nov 2016 at http://cvdnor.b.uib.no/files/2013/08/CVDNOR-Dataand-Quality-Report1.pdf,.

11. Peersen K, Munkhaugen J, Gullestad L, Liodden T, Moum T, Dammen T, Perk $\mathrm{J}$, Otterstad JE. The role of cardiac rehabilitation in secondary prevention after coronary events. Eur J Prev Cardiol. 2017;24(13):1360-8.

12. Burns EM, Rigby E, Mamidanna R, Bottle A, Aylin P, Ziprin P, Faiz OD. Systematic review of discharge coding accuracy. J Public Health (Oxford, England). 2012;34(1):138-48.

13. Donders AR, van der Heijden GJ, Stijnen T, Moons KG. Review: a gentle introduction to imputation of missing values. J Clin Epidemiol. 2006;59(10): 1087-91.

14. Breitling LP. Current genetics and epigenetics of smoking/tobacco-related cardiovascular disease. Arterioscler Thromb Vasc Biol. 2013;33(7):1468-72.

15. Critchley J, Capewell S. Smoking cessation for the secondary prevention of coronary heart disease. Cochrane Database Syst Rev. 2004;1:CD003041 https://doi.org/10.1002/14651858.CD003041.pub2.

16. Moholdt T, Lavie CJ, Nauman J. Sustained physical activity, not weight loss, associated with improved survival in coronary heart disease. J Am Coll Cardiol. 2018;71(10):1094-101.

17. Stewart RAH, Held C, Hadziosmanovic N, Armstrong PW, Cannon CP, Granger CB, Hagstrom E, Hochman JS, Koenig W, Lonn E, et al. Physical activity and mortality in patients with stable coronary heart disease. J Am Coll Cardiol. 2017;70(14):1689-700.

18. Lahtinen M, Toukola T, Junttila MJ, Piira OP, Lepojarvi S, Kaariainen M, Huikuri HV, Tulppo MP, Kiviniemi AM. Effect of changes in physical activity on risk for cardiac death in patients with coronary artery disease. Am J Cardiol. 2018;121(2):143-8.

19. van Halewijn G, Deckers J, Tay HY, van Domburg R, Kotseva K, Wood D. Lessons from contemporary trials of cardiovascular prevention and rehabilitation: a systematic review and meta-analysis. Int J Cardiol. 2017;232: 294-303.

20. Olsen SJ, Schirmer H, Bonaa KH, Hanssen TA. Cardiac rehabilitation after percutaneous coronary intervention: results from a nationwide survey. Eur J
Cardiovasc Nurs. 2018;17(3):273-9. https://doi.org/10.1177/ 1474515117737766 Epub 2017 Oct 19.

21. Rutledge T, Redwine LS, Linke SE, Mills PJ. A meta-analysis of mental health treatments and cardiac rehabilitation for improving clinical outcomes and depression among patients with coronary heart disease. Psychosom Med. 2013;75(4):335-49.

22. Navarese EP, Robinson JG, Kowalewski M, Kolodziejczak M, Andreotti F, Bliden K, Tantry U, Kubica J, Raggi P, Gurbel PA. Association between baseline LDL-C level and Total and cardiovascular mortality after LDL-C lowering: a systematic review and meta-analysis. Jama. 2018;319(15):1566-79.

23. Stroes ES, Thompson PD, Corsini A, Vladutiu GD, Raal FJ, Ray KK, Roden M, Stein E, Tokgozoglu L, Nordestgaard BG, et al. Statin-associated muscle symptoms: impact on statin therapy-European atherosclerosis society consensus panel statement on assessment, Aetiology and Management. Eur Heart J. 2015:36(17):1012-22

24. Hastie CE, Padmanabhan S, Slack R, Pell AC, Oldroyd KG, Flapan AD, Jennings KP, Irving J, Eteiba $H$, Dominiczak AF, et al. Obesity paradox in a cohort of 4880 consecutive patients undergoing percutaneous coronary intervention. Eur Heart J. 2010;31(2):222-6.

25. Pedersen SS, von Kanel R, Tully PJ, Denollet J. Psychosocial perspectives in cardiovascular disease. Eur J Prev Cardiol. 2017;24(3_suppl):108-15.

26. Richards SH, Anderson L, Jenkinson CE, Whalley B, Rees K, Davies P, Bennett $P$, Liu Z, West R, Thompson DR, et al. Psychological interventions for coronary heart disease. Cochrane Database Syst Rev. 2017 Apr 28:4: CD002902. https://doi.org/10.1002/14651858.CD002902.pub4.

27. Pogosova N, Saner H, Pedersen SS, Cupples ME, McGee H, Hofer S, Doyle F, Schmid JP, von Kanel R. Psychosocial aspects in cardiac rehabilitation: from theory to practice. A position paper from the cardiac rehabilitation section of the European Association of Cardiovascular Prevention and Rehabilitation of the European Society of Cardiology. Eur J Prev Cardiol. 2015;22(10):1290-306.

\section{Publisher's Note}

Springer Nature remains neutral with regard to jurisdictional claims in published maps and institutional affiliations.

Ready to submit your research? Choose BMC and benefit from:

- fast, convenient online submission

- thorough peer review by experienced researchers in your field

- rapid publication on acceptance

- support for research data, including large and complex data types

- gold Open Access which fosters wider collaboration and increased citations

- maximum visibility for your research: over $100 \mathrm{M}$ website views per year

At $\mathrm{BMC}$, research is always in progress.

Learn more biomedcentral.com/submissions 